\title{
Study on Design Rainstorm Profile in Liuzhou City Based on Pilgrim \& Cordery Method
}

\author{
Xiaoling Su, Dong Xie*, Lei Liu, Chunrong Liang, Zhourong Liu, Yu Li, Qiu Lan, Le Ren \\ Liuzhou Meteorological Bureau, Liuzhou, China \\ Email: ‘38736716@qq.com
}

How to cite this paper: Su, X. L., Xie, D. Liu, L., Liang, C. R., Liu, Z. R., Li, Y., Lan, Q., \& Ren, L. (2019). Study on Design Rainstorm Profile in Liuzhou City Based on Pilgrim \& Cordery Method. Journal of Geoscience and Environment Protection, 7, 136-144.

https://doi.org/10.4236/gep.2019.73007

Received: November 26, 2018

Accepted: March 25, 2019

Published: March 28, 2019

Copyright $\odot 2019$ by author(s) and Scientific Research Publishing Inc. This work is licensed under the Creative Commons Attribution International License (CC BY 4.0).

http://creativecommons.org/licenses/by/4.0/

\begin{abstract}
Liuzhou City is located in Guangxi Zhuang Autonomous Region of China. It has a warm and rainy climate and belongs to the middle subtropical monsoon climate. It is a rainstorm and flood-prone area. The work of flood drainage and waterlogging prevention is very important. The "minute to minute" rainfall process data of Liuzhou National Meteorological Observation Station from 1975 to 2014 and the Pilgrim \& Cordery method were used to estimate the short-time design rainstorm profile of Liuzhou City, and the profiles of the rainfall lasting for $30,60,90,120,150$, and 180 min were obtained. The research shows that the same rain duration and different recurrence period conditions are consistent with the rainstorm profile. The rainfall duration of $30,60,90,120$, and 180 min generally shows single-peak rainstorm profile, and the rainfall duration of $150 \mathrm{~min}$ shows double-peak rainstorm profile. Most peaks of each short-time design rainstorm profile are at or ahead of the $1 / 3$ part of the entire rainfall process. During the same recurrence period, the rainfall in peak period fluctuated with the increase of the duration, and the intensity of rainfall increased with the prolonging of the recurrence period.
\end{abstract}

\section{Keywords}

Liuzhou City, Pilgrim \& Cordery Method, Short-Time Rainstorm, Design Rainstorm Profile

\section{Introduction}

Affected by the urbanization effect, the occurrence probability and rainfall intensity of short-time high-intensity local rainstorm in the central area of the city are greatly increased, which poses great pressure on urban drainage and flood flowing in river (Chen \& Li, 2017). The design rainstorm profile plays a vital role 
in the planning and design of urban drainage pipe network, and is the basis for obtaining the rainwater runoff process line. Different rainstorm profiles will lead to significant differences in the calculation results of rainfall runoff (Jiang, 2015). Under the same average rainfall intensity during the confluence duration, the rain intensity of the triangle rain profile in the middle or rear part of the rain peak is more than $30 \%$ larger than the uniform rain profile (Geng et al., 1998). Liuzhou has a mid-subtropical monsoon climate with a warm and rainy climate. It is a flood prone area, and flood prevention and waterlogging prevention are very important (Xie et al., 2018).

In this paper, we use the "minute-minute" rainfall process data of Liuzhou National Meteorological Observation Station from 1975 to 2014 to estimate the short-time design rainstorm profile of Liuzhou City, and we get the profiles of the rainfall lasting for $30,60,90,120,150$, and $180 \mathrm{~min}$ by using the Pilgrim \& Cordery method.

\section{Data and Methods}

\subsection{Rainfall Data}

Minute to minute rainfall process data, also known as the mean rainfall process data at a time step of one minute, at Liuzhou National Meteorological Observation Station during 1975-2014 were used. The rainfall data could meet the requirements of reliability, consistency and representation. We also conducted an "annual maximum method", a well-known method which can select the largest rainfall from each annual rainstorm data, and 40 sets of rainfall samples for each duration were obtained.

\subsection{The Method of Pilgrim \& Cordery}

The Pilgrim \& Cordery method places the rain peak period at the position where the probability of occurrence is greatest, and the proportion of the rain peak period in the total rainfall is the average of the proportion of the rain peaks in each field. The position and proportion of the other periods are determined in the same way (Cheng \& Chen, 2018). The specific process is as follows (Huang et al., 2014):

1) Select a sample of heavy rain that lasts for a certain period of time. Selecting the multiple rainfall events with the most rainfall, the more the statistics, the more obvious the statistical significance;

2) The rain duration is divided into several time periods, and the length of the time period depends on the desired distribution time step, which is generally as small as possible. For example, the rainfall sample lasting for 120 min was segmented per $5 \mathrm{~min}$ to infer a rainstorm profile, the rainfall selected in step 1 is divided into 24 segments;

3) For each selected rainfall, the serial number of each time period is determined according to the rainfall from each time interval. The large rainfall corresponds to the small number, and averaging the serial number of each corresponding time period. From small to large, the values are determined as the order 
of rainfall intensity from large to small;

4) Calculate the percentage of rainfall and total rainfall for each time period after sorting, and take the average percentage of each time period, as

$$
\bar{P}=\frac{1}{n} \sum_{i=1}^{n} \frac{R_{i}}{R_{\text {total }}} \times 100 \%
$$

where, $\bar{P}$ is the average percentage of each time period, $n$ is the total number of rainfall periods, $R_{i}$ is the rainfall for each time period and $R_{\text {total }}$ is the total rainfall.

5) Arrange the time period in the maximum possible order determined in the third step and the distribution ratio determined in the fourth step to form a rainfall process line.

\section{Results and Analyses}

\subsection{Proportional Allocation of Each Duration}

According to the principle of $\mathrm{P} \& \mathrm{C}$ method, the normalized processing method is adopted for the rainfall samples in the maximum rainfall process. Normalization method can change the number into decimal between $(0,1)$, mainly for the convenience of data processing. Mapping the data into the range of $0-1$ is more convenient and fast, and should be included in the category of digital signal processing (Zhang et al., 2012; Suliman \& Zhang, 2017). Then each rainfall process factor is evenly divided into $\mathrm{n}$ time periods according to its own rainfall duration at intervals of $5 \mathrm{~min}$. The ordinal number of each time period for each rainfall event is determined in order from large to small of rainfall in different periods. The large rainfall corresponds to the small serial number, then the serial number of each corresponding time period is averaged.

Calculate the ratio of rainfall to total rainfall for each period of rainfall samples, and the average value of the ratio of each rainfall period was obtained after sorting, to ensure that the proportion of rain peak period in total rainfall is taken as the proportion of rain peaks in each rainfall. By placing a peak at the position with the smallest order, you can get the distribution ratio of the design rainstorm for the maximum rainfall process over $30,60,90,120,150$, and 180 minutes (Figure 1).

It can be seen from Figure 1 that most of the design rainstorm profile lasting for 30 - 180 minute are single-peak rainstorm profile. Among them, the design rainstorm profile lasting $30 \mathrm{~min}, 60 \mathrm{~min}, 120 \mathrm{~min}$ and $180 \mathrm{~min}$ is a typical single-peak rainstorm profile. The rainfall peak lasting for 30 minute occurred at the third period, lasting for 60 minute occurred at the fifth period, lasting for 120 minute occurred at the third period, and lasting for 180 minute occurred at the 8th period. Lasting for 90 min rainfall process, there are two distinct peaks appearing in the 4th and 7th time periods respectively. The two peaks are separated by 3 time periods, which is $1 / 6$ of the total rainfall duration. It can also be regarded as a single-peak rainstorm profile from the overall trend, the rainfall peak occurred at the fourth period. Lasting for $150 \mathrm{~min}$ rainfall process, there are 


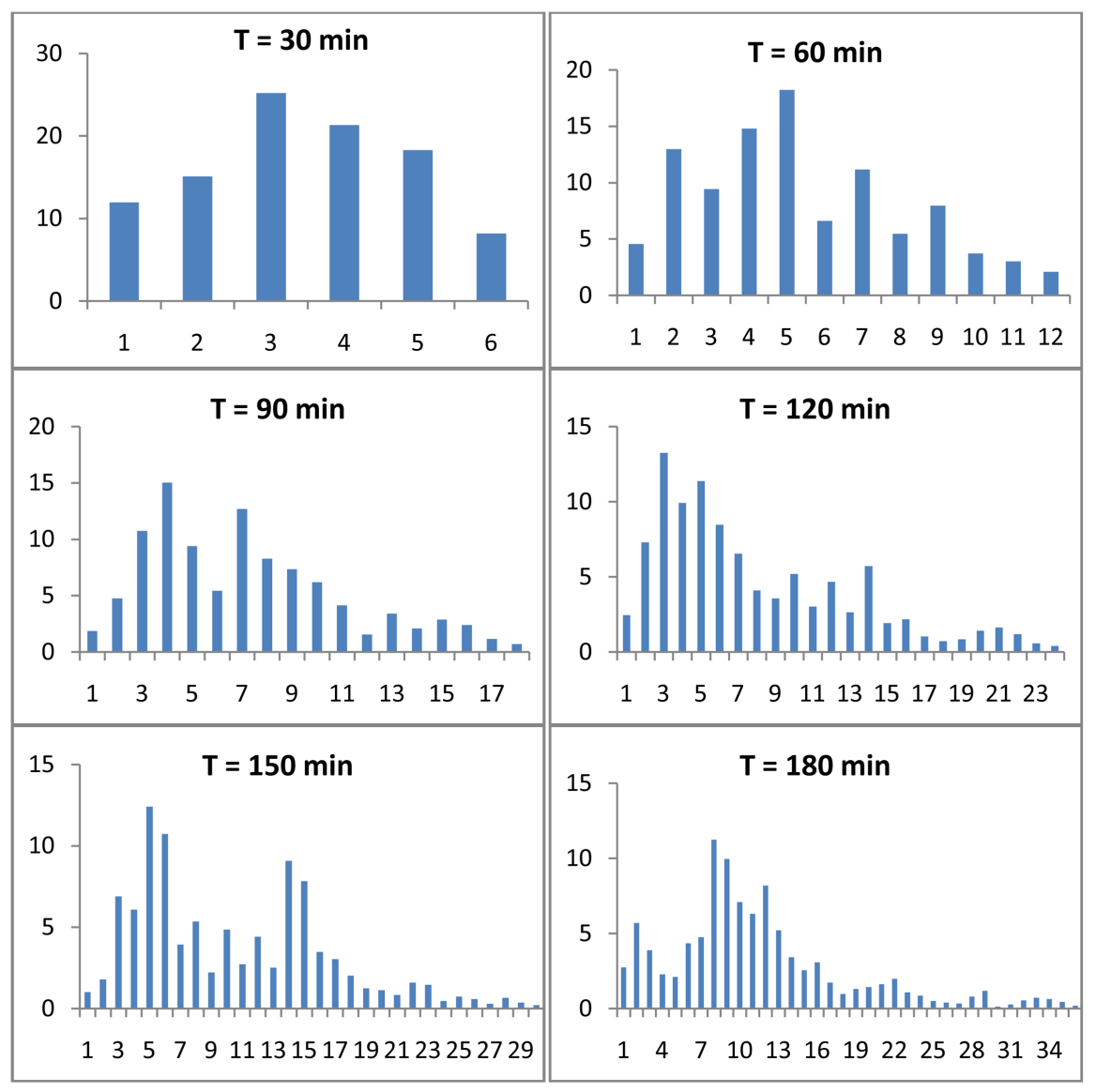

Figure 1. Distribution proportion diagram of short-time design rainstorm profile in urban district of Liuzhou by Pilgrim \& Cordery method. In the picture, the abscissa is the rainfall period, unit: $5 \mathrm{~min}$; the ordinate is the rainfall ratio, unit: $\%$.

two distinct peaks appearing in the 5th and 14th time periods respectively. Two distinct peaks distributed in the front and middle of the whole rainfall process, it's a double-peak rainstorm profile. The rain peak position of the design rainstorm profile lasted for 30 minutes was located at the $1 / 2$ part of the whole rainfall process, $60 \mathrm{~min}$ slightly ahead of the $1 / 2$ part position, $90 \mathrm{~min}, 120 \mathrm{~min}, 150$ min (the first rain peak), $180 \mathrm{~min}$ ahead of the $1 / 3$ points, $150 \mathrm{~min}$ (the second rain peak) slightly ahead of the $1 / 2$ position.

\subsection{Design Rainstorm Profile Results}

After the short-time rainstorm profile distribution ratio is obtained by the Pilgrim \& Cordery method, the rainstorm profile in each recurrence period can be obtained as long as the rainfall amount of each rainfall duration in the corresponding recurrence period is given ( $\mathrm{Li}$ et al., 2015). The rainfall amount of each rainfall duration in corresponding recurrence period is calculated by the rainstorm intensity formula of Liuzhou City (Xie et al., 2017). Rainstorm intensity formula and rainstorm profile all can reflect objectively urban short term severe precipitation patterns. Therefore, it's important to establish a climate demonstration technological system which made urban rainstorm intensity formula 
and rainstorm profile as main contents in China (Zhang et al., 2017; Chen et al., 2017; Gao et al., 2017). Finally, this article has determined rainfall profile by Pilgrim \& Cordery method lasting for $30,60,90,120,150$ and $180 \mathrm{~min}$ in the reappearance periods of 2, 3, 5, 10, 20,30, 50 and 100a (The "a" is the abbreviation of "year", the same below). Calculation result of short-time design rainstorm profile with the interval time of $5 \mathrm{~min}$ in the reappearance period of $2 \mathrm{a}$ in urban district of Liuzhou was shown as Table 1 . Figure 2 shows the calculation result of short-time design rainstorm profile with the interval time of $5 \mathrm{~min}$ in the reappearance period of $2 \mathrm{a}$ in urban district of Liuzhou. The distribution diagram of short-time design rainstorm profile in the reappearance period of $3 a, 5 a, 10 a$, $20 \mathrm{a}, 30 \mathrm{a}, 50 \mathrm{a}$ and $100 \mathrm{a}$ is omitted.

According to the Figure 2 can be found that the rainfall in the same recurrence period is basically the same (within $2 \mathrm{~mm}$ ). The short-time design rainstorm profile in urban district of Liuzhou basically has the characteristics of "single-peak profile, fast coming, high strength, long tail". The short-time design rainstorm profile in recurrence period of $3 \mathrm{a}, 5 \mathrm{a}, 10 \mathrm{a}, 20 \mathrm{a}, 30 \mathrm{a}, 50 \mathrm{a}, 100 \mathrm{a}$ consistent with the recurrence period of 2 a (figure omitted). The rain peak position of the design rainstorm profile lasting for $30 \mathrm{~min}, 60 \mathrm{~min}$ and $150 \mathrm{~min}$ (the second rain peak) were located at or ahead of the $1 / 2$ part of the whole rainfall process, lasting for $90 \mathrm{~min}, 120 \mathrm{~min}, 150 \mathrm{~min}$ (the first rain peak), $180 \mathrm{~min}$ ahead of the $1 / 3$ part of the whole rainfall process. It can be seen from Table 2 that the rainfall at the rain peak by $\mathrm{P} \& \mathrm{C}$ method fluctuates little with duration increased in the same recurrence period, and the recurrence period of $2 \mathrm{a}, 3 \mathrm{a}$, and $5 \mathrm{a}$ exhibits a slight fluctuation trend of "decrease-increase-decrease". The recurrence periods of 10a, 20a, 30a, 50a, and 100a show a slight fluctuation trend of "increasing-decreasing-increasing-decreasing". And rainfall intensity in each duration increased with the prolonging of reappearance period.

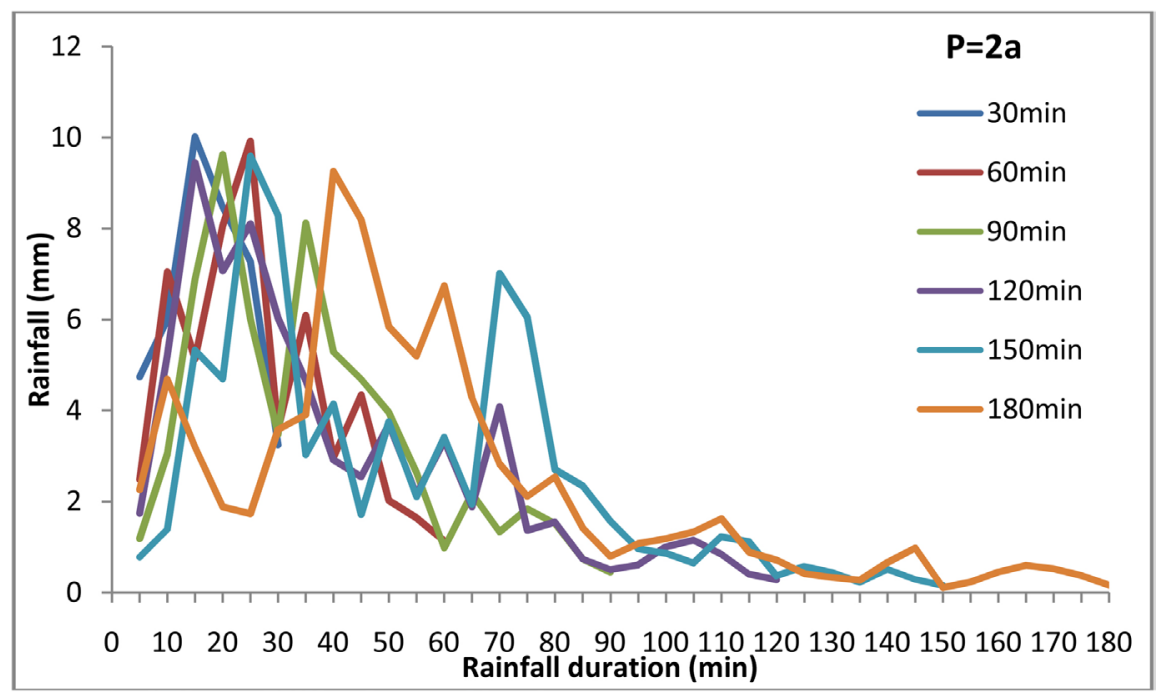

Figure 2. Distribution of short-time design rainstorm profile with the interval time of 5 min in reappearance period of $2 \mathrm{a}$ in urban district of Liuzhou by Pilgrim \& Cordery method. 
Table 1. Designed rainstorm type results of the short-term 5 min interval of the 2a recurrence period of Liuzhou City obtained by the P\&C method.

\begin{tabular}{|c|c|c|c|c|c|c|}
\hline \multirow{2}{*}{$\begin{array}{l}\text { Rainfall } \\
\text { duration } \\
\text { (min) }\end{array}$} & \multicolumn{6}{|c|}{ Rainfall (mm) } \\
\hline & $30 \mathrm{~min}$ & $60 \mathrm{~min}$ & $90 \mathrm{~min}$ & $120 \mathrm{~min}$ & $150 \mathrm{~min}$ & $180 \mathrm{~min}$ \\
\hline 5 & 4.74 & 2.49 & 1.19 & 1.74 & 0.78 & 2.26 \\
\hline 10 & 6.01 & 7.06 & 3.05 & 5.21 & 1.39 & 4.69 \\
\hline 15 & 10.02 & 5.14 & 6.89 & 9.45 & 5.33 & 3.2 \\
\hline 20 & 8.47 & 8.07 & 9.63 & 7.07 & 4.7 & 1.88 \\
\hline 25 & 7.28 & 9.93 & 6.01 & 8.11 & 9.6 & 1.73 \\
\hline 30 & 3.25 & 3.6 & 3.48 & 6.03 & 8.29 & 3.58 \\
\hline 35 & & 6.09 & 8.12 & 4.66 & 3.03 & 3.91 \\
\hline 40 & & 2.97 & 5.29 & 2.92 & 4.15 & 9.26 \\
\hline 45 & & 4.34 & 4.7 & 2.55 & 1.72 & 8.2 \\
\hline 50 & & 2.02 & 3.97 & 3.7 & 3.75 & 5.85 \\
\hline 55 & & 1.64 & 2.64 & 2.15 & 2.11 & 5.19 \\
\hline 60 & & 1.13 & 0.99 & 3.33 & 3.41 & 6.74 \\
\hline 65 & & & 2.19 & 1.88 & 1.94 & 4.29 \\
\hline 70 & & & 1.34 & 4.08 & 7.02 & 2.82 \\
\hline 75 & & & 1.84 & 1.37 & 6.05 & 2.11 \\
\hline 80 & & & 1.53 & 1.55 & 2.7 & 2.55 \\
\hline 85 & & & 0.74 & 0.74 & 2.35 & 1.43 \\
\hline 90 & & & 0.45 & 0.5 & 1.57 & 0.8 \\
\hline 95 & & & & 0.6 & 0.96 & 1.08 \\
\hline 100 & & & & 1 & 0.87 & 1.19 \\
\hline 105 & & & & 1.15 & 0.65 & 1.34 \\
\hline 110 & & & & 0.85 & 1.23 & 1.63 \\
\hline 115 & & & & 0.41 & 1.12 & 0.89 \\
\hline 120 & & & & 0.28 & 0.36 & 0.71 \\
\hline 125 & & & & & 0.58 & 0.41 \\
\hline 130 & & & & & 0.44 & 0.33 \\
\hline 135 & & & & & 0.22 & 0.27 \\
\hline 140 & & & & & 0.51 & 0.66 \\
\hline 145 & & & & & 0.29 & 0.97 \\
\hline 150 & & & & & 0.16 & 0.11 \\
\hline 155 & & & & & & 0.23 \\
\hline 160 & & & & & & 0.45 \\
\hline 165 & & & & & & 0.6 \\
\hline 170 & & & & & & 0.52 \\
\hline 175 & & & & & & 0.37 \\
\hline 180 & & & & & & 0.16 \\
\hline
\end{tabular}


Table 2. Rainy peaks ( $\mathrm{mm}$ ) and peak periods of each of the recurring periods of Liuzhou City obtained by the P \& $\mathrm{C}$ method.

\begin{tabular}{|c|c|c|c|c|c|c|c|c|c|c|c|c|}
\hline $\begin{array}{c}\begin{array}{c}\text { Recurrence } \\
\text { period }\end{array} \\
\text { Rainfall }\end{array}$ & \multicolumn{6}{|c|}{$2 \mathrm{a}$} & \multicolumn{6}{|c|}{$3 a$} \\
\hline $\begin{array}{l}\text { duration } \\
\text { (min) }\end{array}$ & 30 & 60 & 90 & 120 & 150 & 180 & 30 & 60 & 90 & 120 & 150 & 180 \\
\hline $\begin{array}{l}\text { Peak value } \\
\text { (mm) }\end{array}$ & 10.02 & 9.93 & 9.63 & 9.45 & 9.6 & 9.26 & 11.06 & 10.99 & 10.69 & 10.52 & 10.71 & 10.35 \\
\hline $\begin{array}{c}\text { Recurrence } \\
\text { period }\end{array}$ & & & & & & & & & & & & \\
\hline $\begin{array}{c}\text { Rainfall } \\
\text { duration } \\
(\min )\end{array}$ & 30 & 60 & 90 & 120 & 150 & 180 & 30 & 60 & 90 & 120 & 150 & 180 \\
\hline $\begin{array}{l}\text { Peak value } \\
\quad(\mathrm{mm})\end{array}$ & 12.35 & 12.31 & 12.02 & 11.86 & 12.1 & 11.72 & 14.11 & 14.12 & 13.84 & 13.69 & 14.01 & 13.6 \\
\hline $\begin{array}{c}\text { Recurrence } \\
\text { period }\end{array}$ & & & & & & & & & & & & \\
\hline $\begin{array}{l}\text { Rainfall } \\
\text { duration } \\
(\min )\end{array}$ & 30 & 60 & 90 & 120 & 150 & 180 & 30 & 60 & 90 & 120 & 150 & 180 \\
\hline $\begin{array}{l}\text { Peak value } \\
\quad(\mathrm{mm})\end{array}$ & 16.13 & 16.2 & 15.91 & 15.79 & 16.19 & 15.74 & 17.19 & 17.29 & 17.01 & 16.89 & 17.33 & 16.86 \\
\hline $\begin{array}{c}\text { Recurrence } \\
\text { period }\end{array}$ & & & & & & & & & & & & \\
\hline $\begin{array}{l}\text { Rainfall } \\
\text { duration } \\
(\min )\end{array}$ & 30 & 60 & 90 & 120 & 150 & 180 & 30 & 60 & 90 & 120 & 150 & 180 \\
\hline $\begin{array}{l}\text { Peak value } \\
\quad(\mathrm{mm})\end{array}$ & 18.46 & 18.58 & 18.3 & 18.18 & 18.68 & 18.18 & 20.23 & 20.4 & 20.12 & 20.02 & 20.59 & 20.06 \\
\hline $\begin{array}{l}\text { Rainy peak } \\
\text { period }\end{array}$ & 3 & 5 & 4 & 3 & 5 & 8 & 3 & 5 & 4 & 3 & 5 & 8 \\
\hline
\end{tabular}

Note: The data for $150 \mathrm{~min}$ is the peak $(\mathrm{mm})$ of the first rain peak and the peak period.

\section{Conclusion and Suggestion}

In this paper, Pilgrim \& Cordery method is used to estimate the design rainstorm profile in urban district of Liuzhou lasting for $30 \mathrm{~min}, 60 \mathrm{~min}, 90 \mathrm{~min}, 120$ min, $150 \mathrm{~min}$ and $180 \mathrm{~min}$. Main conclusions were as below:

The design rainstorm profile with the same duration in each recurrence period was consistent. Except that the design rainstorm profile lasting for $150 \mathrm{~min}$ showed double-peak profile, and the design rainstorm profile lasting for 30, 60, $90,120,180$ min roughly showed single-peak profile. For the same recurrence period, the precipitation at the rainfall peak fluctuates very little with the rainfall time.

Peak position of each short-time design rainstorm profile was mostly at or ahead of $1 / 3$ part of the whole rainfall process. The rain peak position of the de- 
sign rainstorm profile lasting for $30 \mathrm{~min}, 60 \mathrm{~min}$ and $150 \mathrm{~min}$ (the second rain peak) was located at the $1 / 3-1 / 2$ part of the whole rainfall process, lasting for 90 min, $120 \mathrm{~min}, 150 \mathrm{~min}$ (the first rain peak), $180 \mathrm{~min}$ ahead of the $1 / 3$ part of the whole rainfall process.

Rainfall intensity in the same duration was increased with the prolonging of reappearance period. The engineering designer must use the reappearance period as one of the main considerations when designing the specific design.

The short-time design rainstorm profile in urban district of Liuzhou basically has the characteristics of "single-peak profile, fast coming, high strength, long tail". It shows that when a short-time rainstorm occurs, it is easy to generate large rainfall in a short period. Therefore, when the weather forecast has a short-time rainstorm, all relevant departments of Liuzhou should do the drainage prepare in the first time, increase efforts to dredge and rush, and discharge the accumulated water into the nearby main sewer as soon as possible to prevent the urban waterlogging caused by excessive rainfall intensity.

\section{Acknowledgements}

This work was supported by Scientific Research and Technology Development Plan Project of Liuzhou City in 2017 (2017BH30301).

\section{Conflicts of Interest}

The authors declare no conflicts of interest regarding the publication of this paper.

\section{References}

Chen, J., Zhang, X., Li, J., \& Lin, Z. (2017). Analysis on the Process of a Convective Rainstorm of Stationary Front Triggered by Weak Cold Air. Atmospheric and Climate Sciences, 7, 382-399. https://doi.org/10.4236/acs.2017.73029

Chen, Q., \& Li, M. (2017). Analysis of the Short-Time Rainstorm Profile Based on Drainage and Flood Control Planning. Journal of Express Water Resources \& Hydropower Information, 38, 38-40.

Cheng, D., \& Chen, Z. H. (2018). Comparative Study on Design Rainstorm Profile Used Pilgrim \& Cordery Method by Different Sample Selection Methods. Journal of Meteorological and Environmental Sciences, 41, 132-137.

Gao, J., Pan, J., Wang, M., \& Gu, S. (2017). The Spatial and Temporal Distribution Characteristics of Rainstorm Disaster in Sichuan Province over the Past Decade. Journal of Geoscience and Environment Protection, 5, 1-9. https://doi.org/10.4236/gep.2017.58001

Geng, G. P., Shen, J., \& Fan, R. S. (1998). Study on the Design Rainstorm Profile in Urban. Journal of Advances in Water Science, 9, 41-46.

Huang, H. M., Deng, L., Wang, L. H. et al. (2014). The Derivation and Application of Urban Design Rainstorm and Design Rain Profile. Journal of China Rural Water and Hydropower, No. 3, 35-37.

Jiang, M. (2015). Research on the Design Rainstorm Profile in Shanghai under the New Rainstorm Situation. Journal of Hunan Institute of Science and Technology, 28, 69. 
Li, J., Liu, Z. S., Xue, X. et al. (2015). Analysis of Rainfall Characteristics and Rainfall Profile in Changchun City. Journal of China Water \& Wastewater, 31, 100-104.

Suliman, A., \& Zhang, Y. (2017). Optical-Elevation Data Co-Registration and Classification-Based Height Normalization for Building Detection in Stereo VHR Images. Advances in Remote Sensing, 6, 103-119. https://doi.org/10.4236/ars.2017.62008

Xie, D., Liu, Z. R., \& Jia, X. F. (2017). Revision of Rainstorm Intensity Formula in Liuzhou. Journal of Meteorological Research and Application, 38, 61-63+72.

Xie, D., Su, X. L., Liu, L., Liang, C. R., Liu, Z. R., Li, W., Lan, Q., \& Ren, L. (2018). Study on Design Rainstorm Profile in Liuzhou based on Chicago Method. Journal of Meteorological Research and Application, 39, 72-75.

Zhang, L., Tan, X., Du, Q., \& Wang, J. (2012). Research Performance Assessment Based on T-Indicator. Open Journal of Statistics, 2, 346-351. https://doi.org/10.4236/ojs.2012.23042

Zhang, X., Chen, J., Lai, Z., Zhai, L., \& Lin, M. (2017). Analysis of Special Strong Wind and Severe Rainstorm Caused by Typhoon Rammasun in Guangxi, China. Journal of Geoscience and Environment Protection, 5, 235-251.

https://doi.org/10.4236/gep.2017.58019 